\title{
Saúde dos trabalhadores: cenário e desafios
}

\author{
Workers' health: an overview and challenges
}

Francisco Antonio de Castro Lacaz 1

\footnotetext{
1 Escola Paulista de Medicina, Universidade Federal de São Paulo. Rua Pedro de Toledo 675 São Paulo, SP 04039-032, Brasil
}

\begin{abstract}
This article provides an overview of workers' health services in Brazil, the context of their emergence, their main guidelines as a social policy since 1980, and their development, identifying some difficulties for their implementation. In addition, the study points to some challenges for institutions and society as a whole in overcoming the crisis in this field.

Key words Work; Public Policy; Worker's Health
\end{abstract}

Resumo O artigo traça o contexto de emergência da proposta programática da Saúde do Trabalhador no Brasil e suas características como política social a partir dos anos 80, sua evolução atual, identificando impasses para a sua implementação. Ademais aponta os desafios colocados tanto no nível institucional como da sociedade no sentido de superação da crise da proposta no setor saúde.

Palavras-chave Trabalho; Política Social; Saúde do Trabalhador 


\section{Introdução}

Discorrer sobre a Saúde dos Trabalhadores é, em primeiro lugar, abordar um tema que ainda não atingiu a adolescência, mas que precisa ter discutidos os caminhos que levem a uma maturidade saudável e duradoura.

Por outro lado, pensar o cenário da Saúde dos Trabalhadores compreende resgatar uma história que se inicia no final dos anos 70; assinalar que este campo do conhecimento das relações saúde/doença-trabalho situa-se dentro da Medicina Social Latinoamericana que tem construído seu arcabouço teórico e metodológico desde meados dos anos 70 e, finalmente, enfatizar a sua vertente programática, o que o coloca na interface com a Saúde Pública, a Medicina Social e a Saúde Coletiva, diferenciando-o da Saúde Ocupacional e da Medicina do Trabalho (Laurell, 1991).

É, também, pensar sobre as diversidades epidemiológicas dos agravos à saúde dos trabalhadores que variam desde as doenças provocadas pela introdução das novas tecnologias e pela organização do trabalho, passando pelas “contaminações” por cancerígenos, solventes o benzenismo denunciado em 1982 na COSIPA e que hoje se alastra pelos pólos-petroquímicos de Camaçari na Bahia, de Capuava em São Paulo, de Triunfo no Rio Grande do Sul - e metais pesados; pela surdez de milhares de operários dos mais diversos ramos da produção; pela silicose dos cavadores de poços artesianos da Serra de Ibiapaba no Ceará, pelo gravíssimo problema das intoxicações por agrotóxicos (Freitas et al., 1986) e acidentes com máquinas agrícolas nas atividades rurais, até chegar aos efeitos para a saúde do trabalho escravo de menores e mulheres.

A escolha do marco inicial pode ser aleatória a depender do que move o analista, já que não há uma data marcante de referência. Contudo, se for tomada como ponto de partida a cena política, o "extra-discursivo", é o final dos anos 70 o início desta caminhada.

Trata-se da época em que a Ditadura Militar começa a dar sinais de esgotamento, após sua primeira derrota eleitoral, nas eleições de 1974. Mas, é aqui, nos anos de 1978/79, que se delineiam as mudanças mais significativas no cenário nacional, ou seja, é o momento da retomada do cenário político pelo Movimento Sindical, processo que não por acaso inicia-se no ABC paulista a partir das grandes greves de 1978 nas indústrias automobilísticas e que se espalham por grande parte do território nacional nos meses seguintes, rompendo com a camisa de forças que o Regime Militar impunha à “ordem e à segurança”, após um período surdo de acumulação de forças que ocorre dentro das fábricas, caracterizado pelas "operações tartarugas [e] produção de peças defeituosas” (Frederico, 1979a, 1979b; Humphrey, 1982).

O final dos anos 70 foi um período vivido intensamente pelo movimento social, que no nível mundial tivera como referência os episódios de Maio de 68, com importantes exemplos de solidariedade de classe, de crítica ao poder legitimado na ciência, e com desdobramentos nas mais variadas áreas, inclusive na luta pela saúde e contra a organização do trabalho (Lacaz, 1983; Oddone et al., 1986; Mendes \& Dias, 1991).

Entre nós, a acumulação de forças para dar sustentação a esta luta parte de uma articulação de vários setores do movimento sindical que, em 1978, criam a Comissão Intersindical de Saúde e Trabalho (CISAT) em São Paulo a qual, dois anos depois, tornar-se-ia o "DIEESE da Saúde”, isto é, o Departamento Intersindical de Estudos e Pesquisas de Saúde e dos Ambientes de Trabalho (DIESAT), de caráter nacional, fundado em agosto de 1980, seguindo a experiência vivenciada pelos sindicatos desde 1955 quando da criação do Departamento Intersindical de Estatísticas e Estudos Sócio-Econômicos (DIEESE), cujo papel foi articular o conhecimento de intelectuais de esquerda sem alinhamento partidário, com a necessidade dos sindicatos construírem instrumentos técnicopolíticos para um enfrentamento com a tecnoburocracia estatal no que dizia respeito, já naquela época, à manipulação dos índices do custo de vida (Chaia, 1992). Posteriormente o DIESAT terá importante papel ao subsidiar os sindicatos na discussão sobre a superação da estrutura voltada para o assistencialismo, teimosa herança do Estado Novo, transformandoa em meados dos anos 80 nas assessorias sindicais em saúde e trabalho, importante instrumento de luta pela saúde no trabalho e na sua relação com o Estado.

Se, de um lado, o movimento social dava mostras de maturidade política para enfrentar o Regime Militar, cujo legado de mazelas sobre a vida nacional é visível até hoje, no nível do cenário político mais geral do país era gestado um arco de alianças políticas que levaria à realização de eleições diretas para os governos estaduais, após cerca de vinte anos de intervenção militar.

Assim, em 1982 são eleitos governadores nos Estados de São Paulo, Rio de Janeiro, Minas Gerais, Rio Grande do Sul que assumem compromissos com um amplo leque de forças políticas de caráter suprapartidário e que per- 
mitem avanços importantes na área social, inclusive na saúde, período em que se expressam e se viabilizam várias demandas represadas pela truculência do Regime Militar (Lacaz, 1992). Estabelece-se, neste momento, um novo patamar de relações entre Estado e Sociedade que vai desembocar alguns anos depois na Campanha pelas Diretas Já! que se transformaria também numa das grandes frustrações nacionais da história recente, em função de mais um pacto das elites.

No campo da Saúde, na esteira das proposições internacionais racionalizadoras que se baseiam na chamada Atenção Primária, definida como estratégia de ampliação de cobertura e de participação social durante a Conferência Mundial de Saúde de Alma Ata em 1978, surgem propostas específicas dentro da Organização Mundial da Saúde (OMS) para a atenção à saúde de grupos populacionais de trabalhadores, particularmente os rurais, mineiros e migrantes. Ainda em 1983 o organismo da OMS para as Américas, a Organização PanAmericana da Saúde (OPAS), lança o Documento "Programa de Acción en la Salud de los Trabajadores" (OPAS, 1983) com diretrizes para a implantação de programações em saúde na rede pública de serviços sanitários e voltadas para aqueles que trabalham. Na mesma linha coloca-se a Organização Internacional do Trabalho (OIT) ao adotar em sua 71ạ Conferência Internacional do Trabalho, em 05/06/1985, a Convenção no 161 e a Recomendação no 171 denominadas respectivamente "Convenção e Recomendação sobre os Serviços de Saúde no Trabalho", cujas principais características são o princípio da ampla participação dos trabalhadores, a atuação em equipes multiprofissionais e a sua implementação principalmente a partir de políticas públicas (OIT, 1985), ao contrário do que propunha a Recomendação OIT no 112 de 1959, relativa aos Serviços de Medicina do Trabalho de caráter privado e que "inspiraram" 15 anos depois, em 1975, a criação dos Serviços Especializados de Segurança e Medicina do Trabalho (SESMETs) no Brasil. Frise-se que as proposições de 1985 acompanham uma tendência internacional de ampliação de direitos dos trabalhadores (Parmegianni, 1985), conseqüente de sua luta política e abolem a Recomendação da OIT de 1959. A Convenção no 161 foi ratificada pelo Brasil através do Decreto do Executivo no 127 de 22/05/1991.

Tais manifestações dos órgãos internacionais reforçam a preocupação que vinha amadurecendo entre técnicos da área de Saúde Pública no Brasil e, com a posse, em 1983, dos novos governadores eleitos em 1982, delineia-se a possibilidade de que a Saúde Pública assuma papel ativo na condução de um movimento político-ideológico que ficaria conhecido como os "Programas de Saúde dos Trabalhadores” (PSTs), com experiências que se desenvolveram particularmente em São Paulo, Minas Gerais, Rio de Janeiro, Bahia, Rio Grande do Sul tanto no meio urbano como rural, a partir de 1984-85. Nestas experiências os Serviços de Saúde Pública começam a nuclear a articulação entre as ações de assistência e vigilância (controle da nocividade) dos ambientes e locais de trabalho, envolvendo uma atuação interinstitucional que engloba órgãos da esfera federal como as Delagacias Regionais do Trabalho (DRTs), a Fundação Centro Nacional Jorge Duprat Figueiredo de Segurança e Medicina do Trabalho (Fundacentro), em nível dos estados e a Universidade, com uma abertura para a participação e a gestão dos sindicatos, a valorização do conhecimento/saber dos trabalhadores, ao lado de tornar públicas as informações e dados sobre "de que adoecem e morrem os trabalhadores" (Freitas et al., 1985; Ribeiro \& Lacaz, 1984). Frise-se que estas questões vinham sendo ocultadas pela prática dos Serviços Especializados de Segurança e Medicina do Trabalho (SESMETs) criados a partir de uma imposição do Poder Executivo, através de Portaria do Ministério do Trabalho de 1975 - Portaria MTb no 3.460/75 - com a atribuição de $t u$ telar a saúde dos trabalhadores, aliando os interesses de controle da força de trabalho com a produtividade e o lucro, o que leva-os a manipular resultados de exames, demitir pessoas doentes, negar admissão e autonomia aos seus profissionais, o que contribui claramente para a perda de credibilidade de tais Serviços junto aos trabalhadores, instalando-se uma crise que agravou-se a partir da implantação dos PSTs (Mendes, 1986; Rebouças et al., 1989) e das mudanças introduzidas pelo MTb na Norma Regulamentadora 4, que trata dos SESMETs, questão que será comentada adiante.

De certa maneira a proposta dos PSTs também fora inspirada no modelo da Reforma Sanitária Italiana que teve como um dos seus pilares a luta pela saúde na fábrica e o controle da nocividade do trabalho a partir da centralidade de ação dos sindicatos de trabalhadores nos locais de trabalho, usando como metodologia de intervenção o Modelo Operário Italiano. Como interlocutor externo existia o recémcriado Sistema Nacional de Saúde (sancionado através da Lei no 833 de dezembro de 1978), atuando no nível local através das Unidades Sanitárias Locais (USLs), processo este que atribui ao Sistema Nacional de Saúde (SNS) a 
estratégica tarefa de controlar os riscos e danos à saúde dos trabalhadores dentro e fora dos locais de trabalho (Berlinguer, 1983; Berlinguer et al., 1988; Oddone et al., 1986).

É fora de dúvida que o grau de avanço da luta política dos sindicatos italianos era muito maior do que o atingido pela luta sindical no Brasil no final dos 70, meados dos 80 até os dias de hoje, o que deve ser considerado em qualquer análise que se pretenda. O próprio Movimento pela Reforma Sanitária no Brasil constituiu-se divorciado da luta dos trabalhadores pela saúde no trabalho, apesar da contemporaneidade de suas origens, questão esta que precisa ser analisada e enfrentada, quando se pensa na possibilidade de superação de um certo esgotamento da Reforma Sanitária "tupiniquim” (Cohn, 1992; Lacaz, 1994). Todas estas questões têm origem comum e se articulam com outras, de características estruturais da realidade brasileira e que se referem tanto à fragilidade dos partidos políticos de "esquerda”, como à regulamentação das relações capital e trabalho, consubstanciadas na Consolidação das Leis do Trabalho (CLT) com forte intervencionismo do MTb e que data da época do Estado Novo. Conseqüência desta situação é a extrema dificuldade dos sindicatos se enraizarem nos locais de trabalho, o que impede o desenvolvimento de uma luta duradoura contra a contaminação dos ambientes de trabalho e destes ao ambiente que os circunda, o que deve unir o movimento de trabalhadores e o dos ambientalistas.

Esta pauta de questões teve momento privilegiado de enfrentamento, que foi o processo de elaboração da Constituição Federal de 1988, que teve início nos anos anteriores e que, no campo da Saúde, tem a referenciá-lo a realização da VIII Conferência Nacional de Saúde em março de 1986 e a I Conferência Nacional de Saúde dos Trabalhadores em dezembro do mesmo ano. Marcos históricos da luta pela defesa da saúde como DIREITO e pelo Sistema Único de Saúde, com ampla participação e controle social (MS, 1987), não conseguiram, porém, superar as dificuldades interpostas pelas elites no sentido da democratização das relações nos ambientes e locais de trabalho.

Não se pode, contudo, negar as conquistas no campo da saúde do movimento social a partir da Constituição de 1988, já que tiveram influências e desdobramentos nas constituições estaduais, da Lei Orgânica da Saúde de setembro de 1990, das Leis Orgânicas Municipais e dos Códigos de Saúde, abrindo espaço para o movimento pela descentralização da saúde na perspectiva da meta de municipalização da saúde, cujos percalços e desvios serão enfocados posteriormente (Heimann et al., 1992).

\section{Um período problemático de transição...}

Se os marcos mais importantes no campo da Saúde são lançados em solo semeado ainda na conjuntura política em que se deu a redemocratização mediante a escolha direta de governadores, em nível de panorama nacional após a grande frustração ocasionada pela derrota das Diretas Já!; a morte de Tancredo Neves e os engodos políticos engendrados pela "Nova República” criam uma situação em que se procura vender uma imagem de superação dos problemas crônicos da sociedade brasileira, como a concentração de renda, sem enfrentar de fato as contradições relacionadas aos limites do parque produtivo nacional, ao mercado especulativo e à miopia política das elites nacionais, que perpretaram mais uma transição "pelo alto".

Com a posse de José Sarney, o Brasil viveria um "milagre" efêmero, o do Plano Cruzado, que lançou as bases para o episódio que ficou conhecido como "estelionato eleitoral", ou seja, a eleição de 22 governadores pelo PMDB, partido que havia capitalizado aquele fugaz "sucesso" na campanha eleitoral para as eleições de governadores em 1986. Um traço marcante dessas eleições foi o estreitamento do arco de forças políticas que compuseram o bloco de poder nos estados, até porque tratava-se de candidatos do partido agora hegemônico, o PMDB, e com compromisso baseado num mito, isto é, o Plano Cruzado. Este estreitamento do leque político levou à eleição de governadores com perfil bem mais conservador do que os eleitos em 1982 em Estados tais como São Paulo, Rio de Janeiro, Minas Gerais e este fato teve conseqüências sobre as políticas sociais colocadas em prática pelos governos estaduais a partir de 1987 .

Em nível nacional, a política de saúde, no auge da crise financeira do modelo privatista, passa a implementar os convênios entre a Previdência Social, através do INAMPS, e os governos estaduais mediante o Sistema Unificado e Descentralizado de Saúde (SUDS), iniciando um processo de descentralização das estruturas do INAMPS, mas que logo de início já padece de um grave pecado, isto é, o repasse das verbas para cobrir as novas atribuições de estados e municípios ocorre segundo critérios clientelistas que inviabilizam a construção de um Sistema de Saúde realmente descentralizado e hierarquizado, conforme viria a prescrever a Constituição Federal de 1988 em seu Títu- 
lo VII, Capítulo II, Seção II, artigos 196 a 200, ao tratar do Sistema Único de Saúde (SUS).

Frise-se que, somente em 1994 retoma-se a proposta de descentralização com a assinatura dos “... primeiros quatro convênios com Estados - Paraná, Ceará, Mato Grosso do Sul e Distrito Federal - para a transferência total da gestão das verbas de saúde, em um processo que será fiscalizado diretamente pelas comunidades municipais" (Nassif, 1994) [grifos nossos]. Este processo não acabado apresenta "idas e vindas" que dificultam sua implementação.

A experiência acumulada nos estados e em alguns municípios com os PSTs nos anos 198486, permite a inscrição da saúde dos trabalhadores como atribuição do Sistema Único de Saúde (SUS) na Constituição de 1988, mas a prática adotada pelos governos estaduais que tomam posse em 1987 descaracteriza-os, como ocorreu em São Paulo, ao transformá-los mediante uma lógica semelhante à dos SESMETs (Lacaz, 1992), quando não se procura destruílos, como ocorreu particularmente em Minas Gerais, além do desestímulo em estados como o Rio de Janeiro e Bahia.

Apesar disso, segundo recente levantamento realizado em todo o Brasil sobre os núcleos de atenção à saúde dos trabalhadores, foram contabilizados mais de 180, desde o Acre até o Rio Grande do Sul, alguns patrocinados por Secretarias Estaduais de Saúde - seja pela área assistencial, seja pela área de vigilância epidemiológica/sanitária - e outros por Secretarias Municipais ou por Serviços e Hospitais Universitários (Dias, 1994).

Neste descompasso, o movimento sindical procura garantir as conquistas conseguidas em termos de gestão e participação nos PSTs, mas encontra dificuldades em prosseguir com o seu avanço, na medida em que aparecem na pauta novas demandas, especialmente aquelas relacionadas com o aprofundamento da crise econômico-social, o que traz sérias repercussões sobre o nível de emprego, com reflexos no aumento do desemprego aberto nas grandes cidades brasileiras e na exacerbação do mercado informal de trabalho. Saliente-se que nesta conjuntura ocorre um relativo florescimento de assessorias técnicas em sindicatos, voltadas para as questões de saúde no trabalho, dentro de uma tendência que se delineava no início dos anos 80, particularmente em categorias como os metalúrgicos, químicos-petroquímicos e bancários. Além disso, no final dos 80 , surge o primeiro órgão de assessoria técnica em saúde no trabalho criado por uma Central Sindical, isto é, o Instituto Nacional de Saúde no Trabalho (INST) ligado à Central Única dos Traba- lhadores (CUT), com a finalidade de “...responder a uma necessidade premente da CUT e seus sindicatos: a de contar com um órgão técnico altamente capacitado para assessorá-los nos diversos terrenos da atuação contra os acidentes e doenças do trabalho, nos locais de trabalho; na negociação coletiva das condições de trabalho; nas ações junto às instituições públicas...” (Drumond,1990) [grifos nossos].

Seria esta uma postura a ser adotada pelas outras Centrais Sindicais, em substituição à atuação intersindical de experiência já acumulada entre nós em décadas anteriores (DIEESE e DIESAT) e fazendo parte de uma tendência internacional que teria demonstrado dificuldades na sua trajetória, como ocorreu na Itália, por exemplo (Berlinguer \& Biocca, 1987)?

Ademais, é patente que o movimento sindical brasileiro ainda está por definir uma estratégia global de enfrentamento das questões relacionadas à saúde no trabalho para além da compensação financeira imposta pela lógica mercantilista dos adicionais e da indenização pos facto, a despeito da palavra de ordem norteadora das primeiras ações intersindicais no campo terem sido "guiadas" pela frase: "Saúde não se troca por dinheiro". Da teoria à prática existe um longo caminho a percorrer, o que exige acúmulo político-ideológico e um projeto nacional de hegemonia que atenda aos interesses dos de baixo! Espelho desse recuo é a repetitividade das cláusulas sobre saúde e trabalho dos Acordos Coletivos de Trabalho de categorias como os metalúrgicos e químicos, a diferença do avanço que representaram nos anos 80 (Lacaz \& Campos, 1994). No mesmo sentido, situa-se o paradoxo da defesa do setor público no campo da Previdência Social e da Saúde por algumas Centrais Sindicais em seus eventos nacionais e a inclusão nas pautas de negociação de seus sindicatos de cláusulas que ampliam a cobertura dos Convênios Médicos e do setor privado. Tal postura expressa um elitismo e uma posição que foi se "despolitizando", ao longo do tempo, dos órgãos de representação de ranço corporativista, particularmente aqueles de categorias de setores produtivos de ponta na economia. "Se nas greves do ABC em fins da década de 70, a medicina de empresa foi vista como parte do esforço de controle sobre a força de trabalho, nos anos subseqüentes a demanda por assistência médica diferenciada da oferta da previdência social e, posteriormente do SUS, transformar-se-ia em item da agenda de negociação coletiva..." (Costa, 1994:24-25) [grifos do autor].

Por outro lado, o que acontece no nível da pauta política nacional? Paralelamente ao que 
ocorre nos estados, acontecem em 1988 as eleições para os governos municipais que possibilitam a escolha de vários candidatos com plataformas de perfil democrático e popular em importantes cidades como: São Paulo, Porto Alegre, Angra dos Reis, Campinas, Diadema, Santos, São Bernardo do Campo, Santo André, Contagem, Ipatinga, Monlevade e outras, quando se vislumbra a possibilidade concreta de que tais municípios assumam a questão da saúde e sua municipalização bem como da saúde dos trabalhadores através da programação de saúde pública, mediante os PSTs. De fato, muitos destes municípios passaram a gerenciar serviços de saúde dos trabalhadores dentro da proposta de municipalização da saúde, criando os chamados Centros de Referência em Saúde dos Trabalhadores (CRSTs), tentando aprofundar as experiências existentes no que se refere à gestão e à participação sindical, ao trabalho desenvolvido por equipes multi-profissionais, à articulação interinstitucional e ao funcionamento dos Conselhos Gestores com participação da "sociedade civil” organizada.

Ao mesmo tempo, já na esteira da chamada Lei Orgânica da Saúde, Lei no 8.080/90, procuram introduzir nas leis orgânicas municipais pontos relativos à saúde dos trabalhadores que caminham no sentido de dar maior autonomia à ação do nível local, particularmente no que diz respeito às ações de vigilância em saúde. Apesar de todo um esforço visando à implantação de estruturas de poder imunes às mudanças políticas que pudessem acontecer nas futuras eleições municipais de 1992, percebe-se hoje o paradoxo do processo de municipalização da saúde, conforme aponta um estudo realizado no Estado de São Paulo em que se concluiu que ele tem “... propiciado a extensão de cobertura da assistência médica e a criação de estruturas básicas de gerenciamento dos serviços de saúde ... e contribuído para a politização da questão da saúde com relação ao papel do Estado e da disputa entre os diferentes níveis de governo. Em contrapartida, (...) como está sendo implementada, não constrói com nitidez (...) as bases do SUS, funcionando mais como um processo simultâneo de desconcentração de recursos financeiros e disseminação do atendimento em UBSs. A saúde não é prioridade real de governo(...) está associada à avidez por recursos repassados de outros níveis de governo" (Heimann et al., 1992:174) [grifos nossos]. Quando se trata de municípios grandes o mesmo estudo constata que "onde a presença de setores sindicais é mais forte, observamos preocupações e lutas diretamente ligadas ao tema 'Saúde do Trabalhador'. As lutas, contudo, são no sentido da medicalização, mais consultas e remédios, segundo os moldes de interesse da área privada. As entidades populares não constituem forças capazes de influir decisivamente na política de saúde implementada nos municípios estudados." (Heimann et al., 1992:111) [grifos nossos].

De certa forma foram frustrantes as administrações municipais no que toca à superação das deficiências do setor saúde, até porque a derrota eleitoral de 1992 em muitos casos interrompeu a possibilidade de se dar continuidade ao projeto iniciado em 1989.

No que diz respeito à proposta programática em saúde dos trabalhadores persiste uma séria dificuldade que é a não sensibilização dos profissionais de saúde da rede básica para os problemas de saúde relacionados com o trabalho. Digno de registro, no entanto, é o fato de que a atuação dos PSTs/CRSTs nas grandes cidades trouxe uma mudança no perfil e na magnitude das estatísticas de doenças profissionais no país - apesar da persistência do elevado sub-registro - em estados importantes como São Paulo, Minas Gerais, Rio de Janeiro e Rio Grande do Sul, particularmente a partir de 1990 até 1992 (Lacaz, 1993b), ao lado de desenvolverem sistema de análise de dados de doenças e acidentes do trabalho, que permite estudos epidemiológicos que deveriam ser realizados e trabalhados pela Previdência Social caso efetivamente atuasse como seguradora, na perspectiva do planejamento visando ao controle da insalubridade e periculosidade dos ambientes e condições de trabalho (Diesat, 1993).

A mesma modificação não ocorre no nível das estatísticas de acidentes tipo e de trajeto, mesmo após a Lei no 8.213/91 relativa aos Benefícios da Previdência Social que amplia sobremaneira a possibilidade de notificação dos acidentes, além da empresa. Paradoxalmente, os dados publicados em 1993 e 1994, acompanham a tendência de queda do número absoluto que vem ocorrendo desde 1987, fato que estaria também a refletir o descredenciamento dos hospitais contratados pela Previdência Social para atendimento às vítimas dos acidentes de trabalho alegando a não cobertura financeira dos gastos, e a inobservância pela caótica rede de hospitais de emergência - inclusive os públicos e universitários -, da burocracia de papéis imposta pela Previdência Social para o registro destes acidentes. Aliado a isto persiste a recusa da notificação dos acidentes e doenças do trabalho pelas empresas e até a omissão do próprio trabalhador, premido pela ameaça de demissão, se o fizer. 
Quando se analisa a situação dos organismos da esfera federal que têm atuação no campo da saúde dos trabalhadores, especialmente aqueles vinculados ao Ministério do Trabalho e ao Ministério da Previdência Social, percebe-se que persiste a dicotomia e a pulverização de ações concorrentes entre tais órgãos e aqueles da área do Ministério da Saúde. Estes diferem dos outros pela maior expressão operacional das Secretarias estaduais e municipais de saúde, através da capilaridade de sua rede de serviços.

Por outro lado, na área do Trabalho e da Previdência Social prevalece a centralização administrativa e a atuação mediante delegação de atribuições que emanam do nível federal às Delegacias Regionais do Trabalho (DRTs) e Postos do Instituto Nacional de Seguro Social (INSS), numa lógica que contraria o princípio da descentralização e da autonomia em nível local. A superação deste "estado de coisas" é central para o avanço de políticas eficientes e eficazes na área da saúde no trabalho. A isso se soma a necessidade de também se superar a fragilidade operacional do SUS que como proposta estratégica é correta, mas que padece de vontade política, ao lado de encontrar sérias resistências conservadoras e dos interesses privados à sua concretização. Para superar isso deverá o SUS sensibilizar "corações e mentes" como parte de uma vasta mobilização no plano político, cultural e sindical (Berlinguer et al., 1988). A pergunta que se impõe no momento é: passará incólume a proposta do SUS à sanha conservadora/neoliberal perpretada na revisão constitucional?

\section{Os desafios se apresentam, como enfrentá-los?}

Diferentemente da conjuntura de 1986 quando a I Conferência Nacional de Saúde dos Trabalhadores adquiriu um caráter mobilizador, positivo e propositivo com vistas ao processo constituinte, o momento da II Conferência Nacional de Saúde dos Trabalhadores assumiu um caráter defensivo e de resistência no sentido de se impedir que as conquistas conseguidas fossem aniquiladas pela vaga conservadora e neoliberal, projeto político de fortes raízes, de caráter mundial e que se fortaleceu após persistente embate ao longo de décadas de contra-hegemonia (Anderson, 1995). Assim, em meados dos anos 90 e nos pródromos do próximo milênio antecedem-se inúmeras perplexidades acompanhadas de "quedas de muros" e do socialismo "real" e da decretação do "fim da história" com o triunfo do capitalismo.
Concomitantemente à nova ordem, dá-se o aprofundamento da globalização/cartelização da economia mundial e o apelo aos projetos de qualidade total da produção de bens e serviços, visando à competitividade internacional, com a consolidação do sistema de blocos como a UE e o NAFTA, o que timidamente países da América Latina procuram acompanhar com propostas como o PACTO ANDINO e o MERCOSUL. As "bulas" dos organismos internacionais para economias do terceiro mundo vêm do receituário neoliberal que apresenta como "efeito iatrogênico" um mercado de trabalho no qual subsiste teimosamente o maior nível de desemprego nos países tanto do capitalis mo central como periférico, desde a grande depressão dos anos 20 (Folha de São Paulo, 1994).

A este quadro é necessário agregar aquilo que era anunciado nas barricadas de Paris em 68, o "mal-estar" provocado pelo trabalho na indústria, pelo uso da técnica para o controle despótico, pela sensação de não utilidade do trabalho e pela queda na satisfação e na renda advinda do trabalho. O trabalho vem sendo questionado em sua forma de organização desde os anos 70 na Europa, a ponto de haver sido desencadeada uma verdadeira guerra contra o trabalho pelas novas gerações de trabalhadores em países como a Alemanha e França, o que dificulta enormemente a atuação dos sindicatos, os quais vêm perdendo filiados ano após ano como ocorre na Alemanha, França e Inglaterra, por exemplo. “Tudo isso é reforçado por uma sensibilização crescente em relação aos custos sociais e ecológicos da produção inclusive aqueles não necessariamente concentrados no local de trabalho e em empresas específicas" (Offe, 1989:189). Disto decorre que a luta sindical pela Saúde tem como aliados naturais os movimentos ambientalista e de defesa dos consumidores.

Tendo em conta este panorama é que se deve pensar na pauta de tarefas e embates quando se fala de políticas sociais no Brasil e, dentre elas, as políticas de Saúde no Trabalho.

De início importa demarcar em que limites entende-se que devem ocorrer os ajustes, tão ao gosto do projeto "modernizador" da era Collor! Trata-se de um "duplo movimento" em que: a) de um lado, deve-se recusar o neoliberalismo no campo econômico, já que "as chamadas propostas neoliberais, que foram definidas pelo...'Consenso de Washington'... liberalização/ desregulamentação/ privatização deixaram (...) de ser, nos países da Organização para a Cooperação e Desenvolvimento Econômico (OCDE), a solução mágica para a superação da crise dos anos setenta...nos anos oitenta (...) o credo neo- 
liberal foi absorvido pela tradição corporativista das sociedades européias" (Veiga, s.d.:2);

b) de outro, advogar-se um mínimo de intervenção do Estado nas relações coletivas entre capital-trabalho, com vistas a se atingir contratos de trabalho negociados e adaptados a cada realidade vivida, o que vai de encontro às teses neo-desenvolvimentistas que advogam “...a intervenção do Estado para políticas ativas nas áreas industrial e tecnológica, ignorando a mudança radical por que passam a concepção e a implementação de tais políticas" (Veiga, s.d.:2).

Assim, a par da tarefa louvável de "passar o país a limpo" e da busca da "ética na política" deve-se procurar superar os corporativismos de instituições e categorias, bem como a crítica ao "enxugamento" de Estado, para que as políticas sociais realmente atendam aos interesses da ampla maioria da população brasileira.

A formação de recursos humanos com uma visão clara de sua função social é tarefa central nesta luta. A Universidade precisa se voltar para ela, saindo do alheamento do cotidiano, o que parece estar se modificando com as experiências dos Ambulatórios de Doenças Relacionadas ao Trabalho nos Hospitais Universitários. Neste sentido, vai o papel desempenhado pelo Centro de Estudos de Saúde do Trabalhador e Ecologia Humana (CESTEH) da Escola Nacional de Saúde Pública (ENSP) do Ministério da Saúde que através de seus Cursos de Especialização em Saúde do Trabalhador tem formado centenas de profissionais de variadas profissões, oriundos das várias regiões do país. A multiplicação destes Cursos em outros Estados do Brasil como Rio Grande do Norte (1992), Minas Gerais (1993), Mato Grosso (1994), Paraíba (1995) compõe um quadro de descentralização/regionalização da formação que é salutar por respeitar as especificidades e deve ser estimulada.

Outro sério entrave a ser enfrentado é a questão do financiamento para a Saúde, já que sob a alegação de controle do déficit público, vem ocorrendo uma queda real da verba para o setor. Assim, em 1989 foram gastos $2 \%$ do PIB com Saúde, cerca de US\$ 12 bilhões, e apenas US\$ 7 bilhões em 1993. Esta tendência vem se mantendo, o que leva à proposição de medidas como a Contribuição Provisória sobre Movimentações Financeiras (CPMF) de discutíveis efeitos sobre as mazelas que se propõe a atacar, na medida que se dirige apenas a cobrir o "caixa" dos hospitais (Lacaz, 1995). Saliente-se que o corporativismo, o clientelismo político, a corrupção e a má gestão da "coisa pública" agravam a crise financeira do setor. Para o cus- teio dos danos provocados pelos riscos à saúde dos trabalhadores devem ser adotados mecanismos que considerem a taxação sobre a folha de salários, ampliando as faixas de tarifação existentes, de acordo com o tipo de risco - mais do que o grau - produzido pela empresa e que hoje chega ao máximo de 3\%, quando já foi de cerca de $9 \%$ até 1976 , antes da vigência da Lei Acidentária no 6.367 de 19/10/1976. A isto deve ser agregada a taxação sobre os danos ao meio ambiente provocados pelas empresas poluidoras. Apenas a título de exemplo podem ser citados os seguintes casos de contaminação ambiental: lançamento de mercúrio no Rio Grande, desde a década de 50, um dos afluentes da represa Billings na cidade de Santo André/SP, pela Solvay do Brasil (antiga Eletrocloro) empresa belga do Pólo Petroquímico de Capuava e de dicloroetano em 1992; vazamentos em empresas do Pólo Petroquímico de Camaçari como cloro na CQR, ácido clorídrico na DOW Química, amônia na Nitrofértil, benzeno na Nitrocolor, Nitrocarbono e Deten; vazamento de combustível em Vila Socó, Cubatão/SP pela Petrobrás, com centenas de mortes em 1982; vazamento de 15 toneladas de amônia da Ultrafértil de Cubatão/SP em 1985 e os depósitos de lixo químico com "pó da China” e BHC da Rhodia de Cubatão/SP que contaminam os mangues da Baixada Santista, o que também ocorreu em São Caetano do Sul/SP com os resíduos de BHC da Matarazzo que contaminaram o solo e o lençol freático, empresa esta já desativada (Rebouças et al., 1989; Confederação Nacional dos Químicos/CUT, 1993).

Ademais, a taxação sobre a folha de salários deve ser aliviada pela taxação sobre o lucro e o faturamento das empresas, "capital intensivo", com controle para que não repassem o ônus ao preço final dos produtos e para que não soneguem, como aconteceu recentemente com o "depósito em juízo" das Contribuições para o Fim Social (COFINS). Outra medida a ser adotada com regularidade são as ações regressivas previstas na Lei no 8.212/91 de Custeio da Previdência Social, dirigidas contra as empresas contumazes violadoras das normas de saúde no trabalho e que provocaram verdadeiras epidemias de doenças e acidentes.

Em nível institucional, persiste e se agrava o problema da dicotomia e desarticulação das várias instâncias que atuam no campo da saúde e trabalho, o que não se resolve apenas com a criação de Comissões Interinstitucionais, porque envolve poder e busca de legitimação.

A partir da principal Resolução da II Conferência Nacional de Saúde do Trabalhador, realizada em março de 1994 (MS, 1994), a qual se 
refere à unificação no SUS de todas as ações de saúde do trabalhador - proposição esta combatida pelos representantes do MTb e Fundacentro na Plenária Final da Conferência - à luz dos princípios e diretrizes do SUS, o Setor Trabalho procurou ocupar o espaço que poderia perder. Assim, introduziu modificações na Norma Regulamentadora 4 da Portaria MTb $3.214 / 78$, que trata dos SESMETs e suas competências. A mais importante é a obrigatoriedade de que todo local onde haja trabalhadores, coloque em prática o Programa de Controle Médico de Saúde Ocupacional (PCMSO), envolvendo exames médicos de trabalhadores, avaliação de riscos e seu controle. Tal programa tem sido executado por empresas contratadas de assessoria em recursos humanos, em geral mediante terceirização, constituindo-se num "novo" e amplo mercado de trabalho, que já estava "saturado", para médicos do trabalho e outros profissionais da área, ao lado de incorporar como estratégia a lógica de mercado, passando a "competir" com os serviços públicos de saúde do trabalhador (PSTs-CRSTs) e interferindo claramente para que a "hegemonia" do SUS prevista ao final da II CNST seja dificultada, senão impedida. O mesmo ocorre com a exigência do Programa de Proteção a Riscos Ambientais (PPRA), previsto na Norma Regulamentadora 9 modificada da mesma Portaria, abrindo mercado agora para engenheiros de segurança do trabalho e técnicos. Com isso, o MTb retoma a iniciativa - diante da falta de vontade política do MS, hoje empenhado apenas na questão hospitalar-assistencial e do pouco empenho das forças sociais para colocar em prática as resoluções da II CNST - ao lado de recuperar fortes aliados na condução do mercado de trabalho na área. Isto contraria a meta de que Ministério da Saúde, através do SUS, assuma o controle dos ambientes de trabalho, mediante metodologia epidemiológica aplicada às atividades de vigilância à saúde. Tal competência deveria ocorrer através de ações integradas dentro das atribuições do SUS, acoplando sua ação de "autoridade sanitária" às medidas adotadas pelo Ministério Público, seja no campo da saúde do consumidor e coletiva, seja do meio ambiente.

Para que isso aconteça, o Ministério da Saúde terá que sair de sua letargia, superar sua fragilidade crônica em termos orgânicos na área de Saúde e Trabalho e apoiar as instâncias de nível estadual e municipal que acumularam experiências neste sentido, produzindo modelos de intervenção em vigilância nos ambientes de trabalho que superam o "cartorialismo centralista” da prática das Delegacias Regio- nais do Trabalho do MTb e da "burocracia plutocrática” do INSS. Nesta perspectiva, poderse-ia vislumbrar a montagem de um Sistema Nacional de Vigilância e, como parte dele a "Vigilância em Saúde do Trabalhador” baseada nos Códigos Sanitários nacional e estaduais, que devem prever atividades de inspeção do processo produtivo em todo seu ciclo, da matéria prima ao consumo do produto, sem descurar da qualidade das condições e ambientes de trabalho. Ou seja, a tão decantada "qualidade total" deve pressupor também a boa qualidade das condições de trabalho e do meio ambiente externo. Tal Sistema deve ainda estar calcado na elaboração de normas, “... fruto do compromisso entre o grau de desenvolvimento das forças produtivas, o nível de exigência da sociedade (...), o conhecimento técnico dos especialistas e o poder de polícia do Estado" (Carvalheiro, 1992:26).

São exemplos de medidas nesta linha a formulação de Normas Técnicas relativas a agravos à saúde dos trabalhadores produzidas em São Paulo, a partir de uma articulação interinstitucional nucleada pela Secretaria de Estado da Saúde, com ampla participação de sindicalistas, representantes de empresas, técnicos de vários órgãos e Universidade, o que dá legitimidade à proposta e ao próprio tema objeto da normatização. Trata-se de um embrião de contrato pactuado a partir da iniciativa do setor saúde e que traduz um compromisso com a sociedade e com o coletivo (Lacaz, 1993a). Frisese que tais Normas foram um desdobramento da produção de conhecimento e da qualificação técnico-científica dos profissionais a partir da demanda aos PSTs de trabalhadores intoxicados ou lesionados e que esta iniciativa $s o$ mente foi possível a partir da iniciativa do setor saúde.

São grandes os desafios à frente para que se implante uma efetiva e democrática política social no campo da Saúde dos Trabalhadores, a qual deve necessariamente partir dos níveis regional e local e da ampla participação social, mediante a revitalização dos Conselhos e Comissões gestoras com participação da sociedade civil nos municípios, como os Conselhos Municipais de Saúde, buscando o aprofundamento da municipalização da saúde.

Além disso, outros espaços devem ser utilizados para a condução desta política. Dentre eles situam-se as hoje "esquecidas" Câmaras Setoriais até agora somente ocupadas em discutir e negociar questões econômicas e salariais (Silva \& Navarro, 1994), mas elas podem transformar-se em privilegiado locus negocial em saúde no trabalho, trazendo a possibilida- 
de de abertura dos locais de trabalho para a realização de estudos, com a participação da Universidade, que desvendem a morbi-mortalidade no trabalho, prática tão comum em outros países.

Do mesmo modo, coloca-se a perspectiva do hoje olvidado Contrato Coletivo de Trabalho, o qual somente terá viabilidade de prosperar assumindo como premissas a liberdade de organização nos locais de trabalho, a estabilidade no emprego e a autonomia política dos sindicatos. Estes instrumentos devem ser utilizados contra a grande ameaça do fim do século às economias periféricas - e também das economias centrais - que é o desemprego e a desqualificação da sua força-de-trabalho, mazelas que se evidenciam nas estatísticas publicadas recentemente pelo Instituto Brasileiro de Geografia e Estatística (IBGE). Aos 31 milhões de brasileiros que já não têm cobertura previdenciária de uma População Economicamente Ativa (PEA) de 61 milhões, soma-se a exclusão social de amplos setores de operários da indústria "de ponta" metal-mecânica e eletrônica onde o aumento da produtividade é acompanhado do desemprego. Concomitante ao grande aumento de produtividade nos complexos metal-mecânico e eletrônico brasileiros, de cerca de 40\% nos primeiros sete meses de 1993 e de 23\% no período entre 1991-1993 - o que seria um recorde mundial -, houve uma redução de $10 \%$ no nível de emprego no mesmo período, sendo que 4,9\% nos últimos doze meses (Folha de São Paulo, 1993). Lembre-se que "Esses 'exércitos' de desempregados - que demandam serviços de saúde e assistência social em função de seu baixo consumo e da insegurança social - são a outra face da propalada modernização. O aumento da produtividade com a perda de postos de trabalho seria a marca dos 'ajustes' econômicos do fim do século no mundo, já que o emprego nos setores dinâmicos não é gerado na medida em que aumenta a produtividade. No Brasil, a expansão das grandes massas de excluídos, (...) gera o paradoxo da modernidade que convive com e estimula a barbárie" (Lacaz, 1993c). Em função dessas ameaças os sindicatos têm negociado a flexiblização da jornada de trabalho, conforme o nível da produção.

Assim, qualquer proposta de política social no campo da Saúde, Trabalho, Previdência e Emprego no Brasil não pode desconhecer o $c a$ ráter dos "ajustes" econômicos. Em função disso são temerárias as propostas de modificação da Previdência Social que sugerem aberta ou veladamente a privatização do seguro de acidentes de trabalho, bem como a extinção de benefícios e o pagamento diferenciado pelo atendimento às vítimas de acidentes de trabalho, que surgem até de setores de "esquerda" e que parecem desconhecer o papel redistributivo da Previdência, particularmente num país onde sequer o seguro desemprego tem efetividade. A propósito, projeto de lei do Executivo recentemente transformado na Lei no 9.032/95, que trata do aumento do salário mínimo, trouxe "embutido" a abolição dos benefícios acidentários relacionados ao trabalho, na medida em que equiparou o benefício do auxílio-acidente independentemente do grau de incapacidade que produziu, ao lado de considerar devido o auxílio-acidente em decorrência de acidentes de 'qualquer natureza'. Mais ainda, conforme chama atenção o Promotor de Justiça do Ministério Público de São Paulo, "Esta situação esdrúxula em que se mantém o custeio e não o correspondente benefício, o contrário do que prevê a Constituição no art. 195 (...) e art. 125 da Lei no 8.213/91 ...e o direito constitucional ao seguro contra acidentes do trabalho a cargo do empregador (art. 7o, inciso XXVIII), só nos leva a concluir que estamos perto da privatização do seguro de acidentes do trabalho, considerado o 'filé mignon' securitário" (Monteiro, 1995:7).

A respeito do custeio da Previdência, matéria atualíssima e pouco discutida, assim se referiu o ex-Ministro da Previdência Social, Antonio Brito, em discurso proferido em março de 1993 na Conferência Internacional de Seguridade Social e Reforma dos Fundos de Pensão na América Latina, promovido pelo Instituto das Américas e pelo Banco Interamericano de Desenvolvimento, na Califórnia, “... a estrutura de financiamento da seguridade social no Brasil mostra uma preocupante dependência da folha de salários" (MS, 1993:12). Diante disso, deveria ser financiada com recursos oriundos da folha de salários, do faturamento e do lucro das empresas, conforme prescreve a Constituição Federal de 1988. E é esta dependência quase exclusiva da folha de salários, num ciclo de queda da atividade econômica e aumento do mercado informal, que vem contribuindo para a crise de "caixa" da Seguridade, ao invés de se cumprir o que diz a Constituição, quando grava o faturamento e o lucro.

Por outro lado, grupos conservadores propõem a privatização do sistema de saúde mediante projetos travestidos com o nome de "Planos Básicos de Saúde” que prevêem a cobertura de parcelas restritas da população emprega$d a$. Na mesma linha situam-se proposições de alteração dos encargos sociais devidos pelas empresas e do Fundo de Garantia por Tempo de Serviço (FGTS). O mais grave é que setores 
do sindicalismo compactuam com algumas destas propostas, particularmente o chamado "de resultados" (Brito et al., 1993), o que parece estar "contaminando" outros setores sindicais.

Não se pode compactuar com tais projetos sob pena de adotarmos particularismos em detrimento dos valores maiores de uma sociedade que se pretende justa e democrática.

Para não se correr o risco de "resolver" o varejo esquecendo o atacado, frise-se que as políticas sociais terão forte influência da maneira como o país define a retomada do processo de desenvolvimento após a fracasso da década perdida. "Trata-se de decidir entre a continuidade do 'desenvolvimento' caracterizado pela exclusão e a marginalização social, adotandose a proposta de competitividade (...) calcada na ênfase do crescimento dos setores de 'ponta' da economia (...) que abole postos de trabalho $e$ apresenta produtividade que se alia à queda do emprego, e o modelo alternativo. Alternativo no sentido de não descurar dos setores mais dinâmicos e qualificados, mas que não perpetue como deserdadas as grandes massas de trabalhadores sub-qualificados, cidadãos de 2a classe...Trata-se, ainda, de não 'modernizar', (...), a qualquer custo para competir com Japão, EUA, Alemanha, porque isso é contraditório já que para o Brasil os melhores mercados são os países de desenvolvimento médio (...) porque também precisam de tecnologia de complexidade média" (Lacaz, 1993c:5). Não parece ser este o caminho que vem sendo trilhado no Brasil, conforme mostra pesquisa desenvolvida pelo Programa de Engenharia de Produção da UFRJ que analisou "questionários respondidos por 278 das maiores empresas nos 11 Estados com indice de industrialização mais representativo do país... dos (...) setores da indústria como metalurgia, têxtil e alimentos, (...) concluiu [se] que, até agora, a idéia de qualidade total no Brasil tem apenas um 'efeito cosmético', (...) a maior parte das reestruturações ainda não envolveu grandes investimentos."
“E mais, as empresas privilegiam investimentos em máquinas e equipamentos, deixando o treinamento e a qualificação da mão-deobra em segundo plano" (Folha de São Paulo, 1996). Esta estratégia, diz ainda o autor da pesquisa, é incentivada pela alta "rotatividade da mão-de-obra”, perverso expediente que cria um nefasto círculo vicioso e que continua em pleno uso.

No Brasil, o crescimento da renda interna seja pela ação sindical ou redução da inflação é visto como ameaça, já que o mercado destina pequena parcela do crescimento para satisfazer à população ... E, é isso que deveria acontecer, o Estado deveria recuperar a capacidade interna não somente de investimento, mas de consumo. Em suma, "deve-se reconstruir um modelo de desenvolvimento 'de dentro', isto é, a capacidade de investimento, que foi destruída pelo endividamento, tem que ser recuperada, assim como também o mercado interno ... devese pensar numa política de participação comercial no mercado internacional. (...) não há como discutir se devemos fazer o ajuste, viver numa democracia, ou nos internacionalizarmos... O que se deve buscar é como coordenar estas três necessidades " (Riz, s.d.:5) [grifos nossos].

Estão pois, as políticas sociais em Saúde e Trabalho vinculadas ao projeto de retomada do crescimento que não permaneça excluindo amplos setores da população, projeto este a ser coordenado pela capacidade de investimento do Estado, o qual deve estar escoimado dos interesses privados que o consomem, como demonstrou a CPI do Orçamento, em 1993.

Trata-se da escolha entre a integração social de amplos setores da população, o investimento na qualificação da mão-de-obra, a ampliação do mercado de trabalho, a democratização das relações de trabalho ou o aprofundamento da barbárie já instalada em vários setores da sociedade que sobrevive no submundo da marginalidade nos grandes centros urbano-industriais e nas periferias do país. 


\section{Referências}

ANDERSON, P., 1995. Além do neoliberalismo. In: Pós-Neoliberalismo. As Políticas Sociais e o Estado Democrático. (P. Gentili, org.), pp. 197-202. Rio de Janeiro: Editora Paz e Terra.

BERLINGUER, G., 1983. A Saúde nas Fábricas. São Paulo: Cebes-Hucitec.

BERLINGUER, G. \& BIOCCA, M., 1987. Recent Development in Occupational Health Policy in Italy. International Journal of Health Services, 17:455474.

BERLINGUER, G.; TEIXEIRA, S. F. \& CAMPOS, G. W. S., 1988. Reforma Sanitária, Itália e Brasil. São Paulo: Cebes-Hucitec.

BRITO, I. F.; BARRIOS T. J. \& CAMPOS, R. B., 1993. O nada discreto charme da revisão constitucional e o SUS. Saúde em Debate, 40:13-16.

CARVALHEIRO, J. R., 1992. Qualidade em saúde em tempo de crise. Divulgação em Saúde para Debate, 7:20-27.

CHAIA, M. W., 1992. Intelectuais e Sindicalistas - A Experiência do DIEESE (1955-1990). São Paulo: Editora Humanidades.

COHN, A., 1992. Conhecimento e prática em saúde coletiva: o desafio permanente. Saúde e Sociedade, 1/2:97-109.

CONFEDERAÇÃO NACIONAL DOS QUÍMICOS/CUT, 1993. Câmara Setorial do Complexo Químico Análise e Proposta. São Paulo: CNQ/CUT.

COSTA, N. R., 1994. Políticas públicas, direitos e interesses: reforma sanitária e organização sindical no Brasil. Saúde em Debate, 45:23-29.

DIESAT (Departamento Intersindical de Estudos e Pesquisas de Saúde e dos Ambientes de Trabalho), 1993. Por Uma Política Interministerial de Saúde do Trabalhador. São Paulo. (mimeo.)

DIAS, E. C., 1994. A Atenção à Saúde dos Trabalhadores no Setor Saúde (SUS), no Brasil: Realidade, Fantasia ou Utopia? Tese de Doutorado, Campinas: Faculdade de Ciências Médicas, Universidade Estadual de Campinas.

DRUMOND, J., 1990. Nasce o Inst (Instituto Nacional de Saúde no Trabalho). Informativo INST, 1:2.

FOLHA DE SÃO PAULO, 1993. Produtividade e Miséria. Editorial, 14/11:1-2.

FOLHA DE SÃO PAULO, 1994. Desemprego até quan$d o$ ? Editorial, 13/02:1-2.

FOLHA DE SÃO PAULO, 1996. Modernização É Cosmética, Mostra Pesquisa. 22/01:2-6.

FREDERICO, C., 1979a. Consciência Operária no Brasil. São Paulo: Editora Ática. 2a edição.

FREDERICO, C., 1979b. A Vanguarda Operária. São Paulo: Editora Símbolo.

FREITAS, C. U.; LACAZ, F. A. C. \& ROCHA, L. E., 1985. Saúde Pública e Ações de Saúde do Trabalhador: uma análise conceitual e perspectivas de operacionalização programática na rede básica da Secretaria de Estado da Saúde. Temas IMESC, Sociedade. Direito. Saúde, 2:3-10.

FREITAS, C. U.; SILVA, F. C.; LACAZ, F. A. C.; GALVÃO, L. A. C.; ROCHA, L. E.; DELLATORRE, M. C. C.; CARVALHO, M. L. \& PEINADO, M., 1986. Projeto de Vigilância Epidemiológica no Vale do Ribeira. Saúde Ocupacional e Segurança, 21:107-118.
HEIMANN, L. S.; CARVALHEIRO, J. R.; DONATO, A. F.; IBANHES, L. C.; LOBO, E. F. \& PESSOTO, U. C., 1992. O Município e a Saúde. São Paulo: Editora HUCITEC.

HUMPHREY, J., 1982. Fazendo o 'Milagre': Controle Capitalista e Luta Operária na Indústria Automobilística Brasileira. São Paulo: Vozes/CEBRAP.

LACAZ, F. A. C., 1983. Saúde no Trabalho. Dissertação de Mestrado, São Paulo: Faculdade de Medicina, Universidade de São Paulo.

LACAZ, F. A. C., 1992. O Programa de Saúde dos Trabalhadores da Secretaria de Estado Saúde de São Paulo: a agonia de uma proposta. Saúde em Debate, 36:41-47.

LACAZ, F. A. C., 1993a. Elaborada norma técnica sobre benzeno. Trabalho \& Saúde. 12:8-9.

LACAZ, F. A. C., 1993b. Panorama: Saúde \& Trabalho no Brasil. Decisão, 14:9-11.

LACAZ, F. A. C., 1993c. Desenvolvimento, ambiente, trabalho e saúde. II Conferência Nacional de Saúde dos Trabalhadores. Conferência de Abertura, etapa estadual de Santa Catarina. Florianópolis. (mimeo.)

LACAZ, F. A. C., 1994. Reforma Sanitária e Saúde do Trabalhador. Saúde e Sociedade, 3:41-59.

LACAZ, F. A. C., 1995. Um "mico" para a população: arremedo de política social. Trabalho \& Saúde, 40:22-3.

LACAZ, F. A. C. \& CAMPOS, W., 1994. Demandas sociais em saúde e trabalho. IV Congresso Brasileiro de Saúde Coletiva. Recife.

LAURELL, A. C., 1991. Trabajo y salud: estado del conocimiento". In Debates en Medicina Social (S. Franco, E. D. Nunes, J. Breihl \& A.C. Laurell, orgs.), pp. 249-339. Quito: OPAS.

MENDES, R., 1986. Doutrina e Prática da Integração da Saúde Ocupacional no Setor Saúde: Contribuição para a Definição de uma Política. Tese de Livre Docência, São Paulo: Faculdade de Saúde Pública, Universidade de São Paulo.

MENDES, R. \& DIAS, E. C., 1991. Da medicina do trabalho à saúde do trabalhador. Revista de Saúde Pública, 25:3-11.

MS (Ministério da Saúde), 1987. Relatório Final. I Conferência Nacional de Saúde dos Trabalhadores. Brasília, D. F. (mimeo.)

MS (Ministério da Saúde), 1993. Previdência social no Brasil: gestão ou reforma? Conferência Internacional de Seguridade Social e Reforma dos Fundos de Pensão na América Latina, La Jolla, Califórnia. Brasília: Assessoria de Comunicação Social.

MS (Ministério da Saúde), 1994. Relatório Final. II Conferência Nacional de Saúde do Trabalhador. Brasília, D.F.

MONTEIRO, A. L., 1995. A Lei 9.032/95 e o acidente do trabalho. Boletim de Saúde do Trabalhador, 2:7.

NASSIF, L., 1994. O início oficial do federalismo. Folha de São Paulo, 14/01:2-3.

ODDONE, I.; MARRI, G.; GLORIA, S.; BRIANTE, G.; CHIATELLA, M. \& RE, A., 1986. Ambiente de Trabalho - A Luta dos Trabalhadores pela Saúde. São Paulo: Hucitec. 
OFFE, C., 1989. Capitalismo Desorganizado. São Paulo: Editora Brasiliense.

OIT (Organizacion Internacional del Trabajo), 1985. Actas. Texto del Convenio Sobre los Servicios de Salud en el Trabajo (Convenio no 161). Ginebra: OIT.

OPAS (Organizacion Panamericana de la Salud), 1983. Programa de Acción en la Salud de los Trabajadores. Washington: OPAS. (mimeo.)

PARMEGIANNI, L., 1985. Occupational Health Services in 1984: A Prospective Model. American Journal of Industrial Medicine, 7:91-2.

REBOUÇAS, A. J. A.; ANTONAZ, D.; LACAZ, F.A. C.; RIBEIRO, H. P.; SNELWAR, L. I.; SATO, L.; FREITAS, N. B. B. \& TODESCHINI, R., 1989. Insalubridade Morte Lenta no Trabalho. São Paulo: Oboré Editora.
RIBEIRO, H. P. \& LACAZ, F. A. C., 1984. De que Adoe cem e Morrem os Trabalhadores. São Paulo: DIESAT/IMESP.

RIZ, L., s. d. Crise e desenvolvimento na América Latina: perspectivas de estabilização e de retomada do desenvolvimento. Seminário IRES/DESEP. Campinas.

SILVA, V. P. DA; \& NAVARRO, H., 1994. Um acordo importante. Diário Popular, s/n:4.

VEIGA, P. M., s. d. Crise, estabilização e retomada do crescimento: para além do neoliberalismo e do neodesenvolvimentismo. Seminário IRES/ DESEP. Campinas. (mimeo.) 